\title{
CAPITALISMO GLOBAL E O ADVENTO DE EMPRESAS-REDE: contradições do capital na quarta idade da máquina
}

\author{
Giovanni Alves* \\ Simone Wolf*
}

É certo que, neste princípio de século, o capitalismo vem consolidando profundas transformações, cujas raízes encontram-se fincadas em meados do século passado. Dentre essas, a da sua base produtiva talvez seja uma das mais qualitativas e, pela sua magnitude, o agente motor de outras que, cada vez mais, solapam velhas estruturas e arranjos político-econômicos, denotando uma nova fase histórica do capital. A aplicação da tecnologia informática na produção trouxe mudanças que concretizaram, na contemporaneidade, uma aspiração primordial da economia capitalista: transformar o globo terrestre em um imenso mercado mundial.

No contexto histórico da hegemonia neoliberal, essa aspiração se tornou realidade. Grande parte do planeta encontra-se hoje enredado em uma enorme teia informática, urdida pelas mãos

* Professor livre-docente em Sociologia da UNESPCampus de Marilia, pesquisador do CNPq. Av. Hygino Muzzi Filho, 737, Campus Universitário. Cep: 17525900. giovanni.alves@uol.com.br

* * Professor-Doutor da Universidade Estadual de Londrina - UEL. ROD. C. G. CID, KM (380), CAMPUS UNIVERSITÁRIO. Cep: 86051-990 - Londrina, PR - Brasil. swolff@uel.br.

do capital transnacional, que traz, em seu bojo, novas configurações de poder político e econômico.

A adoção das Tecnologias de Informação e Comunicação (TICs) pelas grandes corporações transnacionais impulsionou a mundialização do capital e contribuiu para o desenvolvimento do capitalismo flexível. Aplicadas à produção industrial e às atividades de gestão, finanças e serviços, as TIC's são capazes de integrar loci globais de produção e reprodução da sociedade de mercadorias. Essas transformações ensejaram a implementação de novas estratégias empresariais com vistas à internacionalização da produção.

As novas tecnologias proporcionaram a estruturação dessas empresas na forma de redes, o que deu mais poder ao grande capital, não apenas na alocação dos fatores de produção e na busca de novos mercados de consumo, mas igualmente na luta contra o trabalho organizado. Nesse sentido, as inovações tecnológicas aparecem como armas da ofensiva do capital na produção, alterando profundamente os termos da luta de classes e as relações dos grandes grupos capitalistas com a classe trabalhadora organizada. 
A preocupação central deste artigo é analisar alguns aspectos dos termos e efeitos dessa nova ofensiva, particularmente para aqueles trabalhadores que se encontram no bojo das mutações estruturais do capitalismo global, a partir da emergência das chamadas empresas-rede.

\section{MUTAÇÕES ESTRUTURAIS DO CAPITALISMO TARDIO}

A história do capitalismo é, antes de tudo, a história do esforço da classe capitalista em controlar e disciplinar a classe trabalhadora para que ela aceite desempenhar um trabalho o mais diligente possível, e se conforme com o fato de que os produtos desse trabalho sejam privadamente apropriados e gerem riquezas apenas para seus empregadores. Com efeito, ao olhar a história por esse prisma, percebemos que, na atualidade, o que assistimos é, fundamentalmente, "a crise de um modo particular de dominação e a luta do capital para criar outro" (Holloway; Pelaez, 1998, p. 28).

No presente, foi a crise do keynesianismofordismo, ou welfare-state, como é mais comumente conhecida, deflagrada, sobretudo nos anos 1970, que impôs ao capital a necessidade de encontrar novas formas de exercer o seu domínio sobre a classe trabalhadora. De acordo com Holloway; Pelaez:

A tecnologia é parte dessa luta [...] O desenvolvimento tecnológico, assim como outros aspectos do desenvolvimento social, é marcado pela tentativa sempre contraditória do capital de colocar arreios na criatividade humana. A "revolução microeletrônica” não é um evento externo [...] é, fundamentalmente, uma tentativa para programar, para reduzir processos sociais complexos a regras simples, transformando a sociedade em algo que pode ser computadorizado. [...] A Nova Tecnologia, que parece oferecer uma base firme para a Nova Ordem, não é menos contraditória que a própria Nova Ordem [...] (1998, p.29).

No plano interno das empresas, a aplicação de novas tecnologias de base microeletrônica pode ser explicada, entre outros fatores, a partir da profunda crise na organização fordista do trabalho, detonada dentro do quadro da crise do wefarestate. Sobretudo nos países economicamente avançados, o aumento do poder de consumo dos trabalhadores e dos subsídios previdenciários, diretivas típicas do welfare-state, levou a um fortalecimento dos sindicatos, bem como a um acréscimo qualitativo de suas reivindicações. Para fugir do excesso de regulamentação e de benefícios trabalhistas, bem como da força de trabalho insurreta, instaurados pela aliança entre o fordismo e o bemestar social, as grandes empresas - originárias dos países onde tais políticas foram levadas de forma mais clássica e, portanto, mais onerosas ao grande capital -, saem em busca de novos mercados de consumo e de trabalho.

É nesse sentido que Clarke afirma que a razão da crise de 1970 não deve ser buscada apenas na "inflexibilidade da produção fordista", mas também na:

... inflexibilidade dos arranjos institucionais, mas tal como ocorreu em períodos de crise anteriores, esta inflexibilidade não era uma característica da tecnologia de produção, mas sim da resistência trabalhista, institucionalizada nas formas de relações industriais e de representação política que foram desenvolvidas como solução provisória de conflitos trabalhistas anteriores (Clarke, 1991, p. 148 - grifo próprio).

Éassim que, mais incisivamente no decorrer da década de 1980, o welfare-state começa a sofrer um paulatino mas decisivo desmantelamento, assinalado pelo surgimento de políticas-econômicas de cunho neoliberal. Em confronto direto com o keynesianismo, o neoliberalismo parte do pressuposto de que a instituição por excelência capaz de dar conta das crises capitalistas é o mercado. Para tanto, é necessário promover a associação de todos os países sob a égide de um mercado mundial, o que supõe uma política comercial comum e a liberalização generalizada de tarifas alfandegárias.

Sob o arrimo da liberalização econômica, as grandes corporações podem agora efetuar, a seu bel-prazer, transações de compra e venda com outros países e empresas, gerando, assim, uma liquidez financeira sem precedentes. A partir detal liquidez, configura-se um grau de internacionalização 
econômica fundamentada sob a égide do capital financeiro, o qual expressa um dos aspectos mais fundamentais do capitalismo contemporâneo (Chesnais, 1996, 2005; Harvey, 2005). Com isso, as formas de acumulação e valorização de riqueza não só foram ampliadas como diversificadas, quantitativa e qualitativamente.

O caráter eminentemente financial das transnacionais demandou e efetivamente criou

... uma rede de malhas permanentemente mutáveis (as ligações de capital e os acordos estratégicos entre as várias companhias transnacionais), unindo uma pluralidade de pólos principais (as maiores companhias transnacionais), os quais se enraízam socialmente nas esferas nacionais e regionais mediante a franchising, a subcontratação e o apelo aos capitais locais (Bernardo, 2000, p. 43).

Nesse contexto, a marca e, em decorrência, o marketing empresarial tornam-se mais um aspecto da produção e dos mais prementes, já que suas estratégias projetam mercadorias, igualmente transnacionalizadas, nos mais diferentes rincões da Terra. Sob a lógica fluida e dispersiva das redes informáticas, portanto, as grandes empresas nada mais são que grandes marcas e alguns laboratórios. De resto, são pequenos pontos espalhados pelo planeta, conectados pelas TIC's. A idéia-chave que orienta esse modelo de empresa é que a produção de bens é

... apenas um aspecto incidental de suas operações, e que, graças às recentes vitórias na liberalização do comércio e na reforma das leis trabalhistas, seus produtos podem ser feitos para eles por terceiros, muitos no exterior. [...] O sucesso dessa fórmula levou as empresas a uma corrida pela ausência de peso: quem possuísse menos, tivesse o menor número de empregados na folha de pagamento e produzisse as mais poderosas imagens, em vez de produtos, ganharia a corrida (Klein, 2002, p.28).

É assim que a aplicação das TIC's nos processos de produção marca uma nova fase histórica do capital em que, aos poucos, a fábrica, emblemática do capitalismo nascente, cede lugar às empresas baseadas na lógica de redes. O mercado dirigido para a produção de massa, que vigorou dos primórdios do capitalismo até a referida crise do keynesianismo-fordismo - no primeiro contexto sendo conquistado por colonização, no segundo por especialização -, demandou a disciplina da fábrica, onde os trabalhadores eram mantidos em confinamento e moldados segundo funções previamente convencionadas pelos padrões de cada tipo de indústria.

Já o mercado atual, caracterizado por um “capitalismo de sobre-produção” (Harvey, 2005; Deleuze, 1992), é dirigido para o produto, isto é, para a venda especulativa em cima de sua "logo" (Klein, 2002). Como tal, encontra-se sob a égide dos serviços e do jogo da bolsa de valores, o que exige o tipo de controle próprio do ambiente informatizado das grandes empresas.

No regime de empresa: as novas maneiras de tratar o dinheiro, os produtos e os homens, já não passam pela antiga forma fábrica. [...] atualmente, o capitalismo não é mais dirigido para a produção, relegada com freqüência à periferia do Terceiro Mundo [...] é um capitalismo de sobreprodução. Não compra mais matéria-prima e já não vende produtos acabados: compra produtos acabados, ou monta peças destacadas. O que ele quer vender são serviços, e o que quer comprar são ações. Já não é um capitalismo dirigido para a produção, mas para o produto, isto é, para a venda para o mercado. Por isso ele é essencialmente dispersivo, e a fábrica cedeu lugar à empresa (Deleuze, 1992, p. 223-224).

Com uma planta extremamente reduzida e fragmentada, as empresas, diferentemente das fábricas, "funcionam não mais por confinamento, mas por controle contínuo e comunicação instantânea” (p. 216). De forma distinta dos registros que mantinham a disciplina na fábrica, a peculiar volatilidade e a pulverização proporcionadas pelas novas tecnologias requerem um controle cifrado, de senhas, capaz de tornar o trabalhador, ao mesmo tempo, espargido e rastreável. Por conseguinte, é um controle insinuante e flexível, que deixa o indivíduo trabalhador permanentemente enredado, pronto para se adaptar aos humores do mercado e à sua cada vez mais ávida sede de inovação e especulação. Essa a razão pela qual:

As conquistas de mercado se fazem por tomada de controle e não mais por formação de disciplina, por fixação de cotações mais do que por re- 
dução de custos, por transformação do produto mais do que por especialização da produção. [...] O serviço de vendas tornou-se o centro ou a 'alma' da empresa. Informam-nos que as empresas têm uma alma, o que é efetivamente a notícia mais terrificante do mundo. O marketing é agora o instrumento de controle social, e forma a raça impudente de nossos senhores. O controle é de curto prazo e de rotação rápida, mas também contínuo e ilimitado, ao passo que a disciplina era de longa duração, infinita e descontínua. (Deleuze, 1992, p. 224)

Na grande empresa contemporânea, esse tipo de controle é favorecido pelas redes informacionais, as quais promovem uma gestão por "modulação, como uma moldagem auto-deformante que mudasse continuamente, a cada instante, ou como peneira cujas malhas mudassem de um ponto a outro" (p. 221 - grifo do autor). Logo, trata-se de um controle que coloca uma verdadeira "coleira eletrônica" naqueles que se encontram sob seu jugo:

A velha toupeira monetária é o animal dos meios de confinamento, mas a serpente o é das sociedades de controle. Passamos de um animal a outro, da toupeira à serpente [...] O homem da disciplina era um produtor descontínuo de energia, mas o homem do controle é antes ondulatório, funcionando em órbita, num feixe contínuo (p. 222223).

O capitalismo global, portanto (e por enquanto), é o capitalismo das empresas-rede, cujo foco é determinado pela ênfase no marketing, em detrimento da fabricação de bens, justamente por permitir às corporações tornarem-se flexíveis, enxutas e ubíquas. Com isso, o

próprio processo de produção - administrado pelas fábricas, responsáveis por dezenas de milhares de empregados efetivos de tempo integral - começou a parecer menos um caminho para o sucesso do que uma pesada responsabilidade (Klein, 2002, p. 28).

Disso decorre o poder e a fragilidade da empresa contemporânea. Se, por um lado, elas se tornam mais rentáveis pela redução de sua base produtiva e empregatícia, bem como pela rápida possibilidade de encontrar mercados de trabalho barato, por outro, seu controle sobre esse processo é dificultado em sua dimensão subjetiva, uma vez que a substituição de uma unidade centralizadora por "nódulos-marca", espargidos mundo a fora, limita a identificação dos trabalhadores com os objetivos da empresa, algo essencial para se moldar uma força de trabalho comprometida com os novos desígnios mercadológicos.

Ademais, esse comprometimento é tanto mais necessário na medida em que o trabalho vivo se revela como o único fator de produção dotado da capacidade de produzir a mais nova e estratégica matéria-prima do capitalismo: informações inovadoras (Zarafian, 2001). Algo que só pode ser conseguido mediante conhecimento engajado dos negócios da empresa. É com esse propósito que se procedem a novas políticas de gestão do trabalho que, tal como as TIC's, também se apresentam como uma ferramenta fundamental e, via de regra, complementar à luta do capital para mobilizar e dominar a capacidade criativa própria do trabalho vivo, de acordo com as novas estratégias empresariais apontadas.

Como veremos a seguir, as novas máquinas de comunicação em rede, as quais inauguraram a quarta idade da máquina, no bojo do paradigma microeletrônico, iriam intensificar globalmente o papel da informação dentro das organizações.

\section{ORGANIZAÇÃO E INFORMAÇÃO SOB A QUARTAIDADE DA MÁQUINA}

O paradigma microeletrônico promoveu mudanças radicais que afetaram toda a economia, envolvendo mudanças técnicas e organizacionais, mudando produtos e processos, criando novas indústrias. No que tange à esfera da circulação, as TIC's igualmente constituíram um novo espaço virtual de informação e comunicação - o ciberespaçoinaugurando o que denominamos de Quarta Revolução Tecnológica, que constitui o desdobramento radical da Terceira Revolução Tecnológica, a revolução informática, também conhecida como Terceira Revolução Industrial, que marca o desenvolvimento da grande indústria pós-fordista.

As inovações tecnológicas oriundas da Quarta Revolução Tecnológica incorporaram o 
paradigma microeletrônico ou informacional na arquitetura de redes telemáticas ou de comunicação, dando um salto qualitativo na maquinaria informacional que, como vimos, tornaram-se "nódulos" de um sistema de máquinas combinadas. A rede intensificou, no circuito da produção de capital, as atividades típicas de informação: educação, pesquisa e desenvolvimento, serviços de consultoria e informações, comunicações, burocracia pública e privada, serviços financeiros, etc.

Desse modo, as máquinas informacionais não só conformam o arcabouço técnico-organizacional no âmbito dos processos de produção dos grandes grupos em rede, como também as próprias novas tecnologias, como "mercadorias embarcadas", que permeiam nosso cotidiano e embasam o todo orgânico da produção do capital. As máquinas, assim, se tornam não apenas instrumentos de produção, mas de reprodução social, uma vez que incorporam (e constituem) redes de virtualização nas instâncias de consumo e de manipulação social, exigindo uma maior capacidade de representação estética.

Éa esse salto qualitativo, ou "salto quântico", na evolução do maquinário no capitalismo, que se refere a Quarta Idade da Máquina. Conforme Mandel (1982), a relação com a máquina e sua representação altera-se dialeticamente em cada um dos estágios qualitativamente diferentes de desenvolvimento tecnológico. O conceito de Quarta Idade da Máquina atualiza a periodização de Mandel sobre o capitalismo tardio, ao considerar a revolução das redes informacionais, ou das TIC's, como a última grande revolução tecnológica engendrada pelo modo de produção capitalista. É com ela que se constitui o ciberespaço, rede interativa ou controlativa de produção e reprodução social.

Assim, a periodização das revoluções tecnológicas engendradas pelo capital, desde a revolução industrial, originária em fins do século XVIII e primórdios do século XIX, ficaria deste modo:

\footnotetext{
1 A expressão “salto quântico” é utilizada por Frederic Jameson, inspirado por Ernest Mandel, ao tratar dos estágios de revolução tecnológica no interior do próprio
} capital (Jameson, 1988).
- Primeira Idade da Máquina: a produção de motores a vapor a partir de 1848.

- Segunda Idade da Máquina: a produção de motores elétricos e de combustão a partir dos anos 90 do século XIX.

- Terceira Idade da Máquina: a produção de motores microeletrônicos e nucleares que vai dos anos 50 até os anos 70 do século XX.

- Quarta Idade da Máquina: a produção de máquinas microeletrônicas informacionais e sua integração em rede interativa ou controlativa (ciberespaço) a partir dos anos 80 do século XX.

A cada salto tecnológico, com sua respectiva produção de máquinas, corresponde uma forma de mercadoria predominante, a partir da qual se constitui a estrutura sócio-reprodutiva. É possível dizer que a forma-mercadoria da Quarta Idade da Máquina é a "mercadoria-informação", que constitui e integra, na etapa da produção, elementos de gestão, logística, design, planejamento e marketing. O insumo-informação é um dos componentes mais estratégicos da nova produção capitalista. É pela informação que não só se otimizam processos e produtos, ${ }^{2}$ mas que se organiza a produção.

Enquanto a Primeira, Segunda e Terceira Idades da Máquina pertenciam à época das revoluções industriais, a Quarta Idade da Máquina pertence à época da Revolução Informacional, que promove uma ruptura no desenvolvimento da Máquina - muito embora a Quarta Idade da Máquina ocorra no interior da Terceira Revolução Industrial, o que explicita o caráter radicalmente contraditório da atual revolução industrial. É isso que leva Jean Lojkine a considerar a "revolução informacional", procedente da Quarta Idade da Máquina, de magnitude equivalente ou maior do que aquela operada pela "revolução da máquinaferramenta".

${ }^{2}$ Como iremos verificar adiante, as inovações tecnológicas e inovações organizacionais compõem um todo orgânico complexo de aparatos técnico-organizacionais, voltados para a manipulação de informações "capturadas" do saber-fazer do trabalho vivo. 
Instrumento e máquina-ferramenta se inscrevem, ambos, nas formas de objetivação, pelo homem, do trabalho manual, do trabalho de manipulação da matéria. Ora, os novos meios informáticos de trabalho abrem uma nova era na história da humanidade: a da objetivação, pela máquina, de funções abstratas, reflexivas, do cérebro - não mais funções cerebrais ligadas à atividade da mão (Lojkine, 1995, p.87).

Na medida em que a revolução das redes informacionais combina máquinas microeletrônicas flexíveis em redes comunicacionais, ao mesmo tempo interativas e controlativas (ciberespaço), constitui-se o que denominamos de "cooperação complexa”, com a interpenetração - não a fusão ou substituição - das forças produtivas materiais e forças produtivas sociais e humanas, ou do material e do informacional. Portanto, o que consideramos “cooperação complexa” é a cooperação desenvolvida pela grande indústria capitalista "afetada de negação”, na medida em que se intensificam as potencialidades contraditórias tecnológicas na Quarta Idade da Máquina, contradições enredadas sob as teias de um novo tipo de oligopólio mundial tecido pelas empresas-rede.

\section{OLIGOPÓLIO MUNDIAL E O ADVENTO DAS EMPRESAS-REDE}

A partir do novo padrão de acumulação criado pelas políticas neoliberais, as grandes companhias, alicerçadas em um só produto e com uma rígida hierarquia estabelecida sobre um modelo piramidal e centralizador do processo produtivo característica da produção fordista - transformamse em firmas fundamentadas em processo. Ao conjugar a estrutura vertical e a horizontal, essa disposição reconfigura a forma de integração empresarial, constituindo um modelo rede de empresa.

O modelo redeé mais adequado para edificar uma estrutura organizacional enxuta e flexível, portanto mais condizente com o tipo de mercado estabelecido sob a mundialização do capital. Daí a atual tendênciaà terceirizaçãoe (ou) à desintegração vertical da produção, em substituição à integração vertical de departamentos dentro de uma mesma empresa.
Em contraposição ao modelo piramidal, o modelo rede é definido como um conjunto de processos produtivos, referidos uns aos outros por meio de conexões estabelecidas sob a forma de uma constelação. Essa constelação toma a forma de rede por atar os múltiplos pontos desses processos através de vários feixes, que se espalham e permitem interligar várias unidades produtivas (Gussi; Wolff, 2001). Aqui sobressai a idéia de fluxo e processamento de informações, em detrimento de procedimentos estanques e previamente definidos, tal como se dava sob a estrutura hierarquizada, própria da forma de integração fordista.

No modelo rede, as unidades produtivas conformam-se como semi-autônomas, mais aptas para suprir crescentes variações do mercado. Tal arranjo possibilita amenizar eventuais efeitos negativos que uma coligada poderia exercer sobre outras, permitindo que problemas pontuais sejam detectados e resolvidos, sem que haja interferências relevantes no processo produtivo em sua totalidade. Como indica Chesnais (1996, p. 103-104), é através dessas redes que "a grande companhia pode estabelecer um controle estrito sobre parte das operações de outra empresa, sem precisar absorvê-la. Essa a originalidade das empresas em rede" (grifo nosso).

A forma mais bem acabada desse modelo é aquela que incorpora, em seu sistema, não só a diversificação de produtos e serviços, mas também de seus projetos e planejamentos, bem como dos profissionais especializados nessas funções. Nesse novo modelo de empresa, a principal chave competitiva passa a ser inovação, em detrimento de massificação. Os produtos passam a ser diversificados, com vistas a atender a um mercado cada vez mais global, heterogêneo e competitivo. Em vista disso, sobretudo nas grandes corporações, o conhecimento científico e a inovação tecnológica convertem-se em departamentos fundamentais (P\&D), que passam a receber maciços investimentos e recursos. A formação de "alianças estratégicas”, isto é, de "acordos de cooperação relativos à tecnologia, constituídos entre os grandes grupos, dentro dos oligopólios” (Chesnais, 1996, p. 165), caracteriza 
bem como a dinâmica das redes tornou-se fundamental na catalisação de informações estratégicas inter-grupos, permitindo a extensão de seus domínios nas mais diversas áreas do conhecimento aplicado.

No final desse processo, encontram-se as terceirizadas e (ou) subcontratadas, que, além de aplicarem as tecnologias de produção projetadas por suas matrizes, tratam da comercialização dos novos produtos e serviços por elas desenvolvidos, tornando-se, dessa forma, também suas fornecedoras. Ao tornarem suas contratadas, ao mesmo tempo, suas clientes, as empresas-mãe conseguem aumentar, qualitativa e quantitativamente, seu mercado de consumo.

Efetivamente, a descentralização do processo produtivo demanda o uso dessas tecnologias como forma de melhor gerenciar a integração das diversas cadeias produtivas que compõem as grandes corporações. Tal descentralização permite às grandes empresas abarcarem rápida e eficientemente novos mercados - tanto de trabalho como de consumo -, ao mesmo tempo em que as conecta em uma rede capaz de integrá-las em tempo real. De acordo com Bianchetti:

A pretensão atual é eliminar as distâncias e, através da estratégia tecnológica do on-line, submeter o tempo a critérios que não obedeçam mais ao deus Chronos, com seus tempos e datas sucessivas, isto é, cronológicas. O objetivo é a busca da materialização da expressão here and now.[... Falando em termos técnicos e sociais, a passagem do modelo de produção e regulação fordista para o da acumulação flexível imprimiu um ritmo mais acelerado na produção, que passou a depender de outros meios para a sua circulação, fatores potencializados pelas novas tecnologias de informação e comunicação. Neste novo padrão de produção e circulação, a ciência e a tecnologia possibilitam uma produção deslocalizada, desterritorializada e desespacialidazada. Isto é, a distância já não é mais um fator impeditivo [...] façanha só tornada possível graças ao desenvolvimento das novas TIC’s. (Bianchetti, 2000, p. 40-42).

Em um mercado efêmero, como o da economia mundializada, a troca rápida de informações é essencial, não só para garantir a vanguarda na adaptação de seus produtos em um contexto marcado pela diversidade cultural e regimental, mas tam- bém para otimizar as suas diretrizes mercadológicas. De fato, a utilização das redes permite prever, em grande medida, o grau de aceitação dessas inovações no mercado, bem como as oscilações da demanda efetiva nos diferentes pontos do planeta, possibilitando uma produção enxuta e direcionada. Por conseguinte, o consumo torna-se altamente personalizado, viabilizando estoques drasticamente reduzidos e, pois, um planejamento e uma racionalização mais eficazes sobre os investimentos estratégicos empresariais.

Sob o modelo rede, as grandes corporações expandem e aprofundam seu domínio através da apropriação e difusão da inovação, bem como dos meios técnicos necessários para realizar tal prática. Essa difusão é conseguida porque o modelo rede, quando operado em aliança com as novas TIC's, permite, além de uma maior integração dos processos, uma interatividade sem precedentes entre os vários elos do processo produtivo, tendo em vista sua lógica conectiva e múltipla. Essa versatilidade é a base da flexibilidade, fator indispensável ao processo de inovação das empresas de ponta, uma vez que atua como um canal permanente de aporte de informações relativas à melhoria de seus processos e produtos, em conformidade com as variações do consumo e com as localidades de suas terceirizadas e (ou) subcontratadas.

Outra vantagem da conjunção do modelo rede com as novas TIC’s é a centralização das decisões corporativas, tanto entre suas unidades produtivas autônomas como no interior de cada coligada em particular, o que torna possível um gerenciamento mais padronizado das atividades e estratégias empresariais. A utilização das teias telemáticas é crucial na agregação de informações cada vez mais dispersas, viabilizando a concentração das decisões dessas empresas, ao mesmo tempo em que permite a extensão de seus tentáculos nos mais variados campos produtivos e financeiros. O controle e acesso das informações sobre as variações do mercado, bem como a rapidez com que esses dados chegam e são tratados, tornam-se fatores fundamentais para a coordenação ótima das diversas atividades econômicas, inclusive finan- 
ceiras, agregadas em torno das grandes corporações.

Como vimos, a mundialização financeira engendrou um tipo de organização eminentemente rentista. A lógica das redes permite que essas corporações ampliem sua lucratividade não apenas na produção e comercialização própria do seu grupo, mas, sobretudo, na especulação das vantagens retiradas dos ativos desvalorizados (bens de capital e força de trabalho) em sua relação geopolítica com suas subcontratadas (Harvey, 2005).

Essa nova estratégia tecnofinanceira configura aquilo que Dunning (1988) denomina de "multinacionais de novo estilo", que se apresentam como "o sistema nervoso central de um conjunto mais amplo de atividades (...) cuja função primordial consiste em fazer progredir a estratégia competitiva global e a posição da organização que está no seu âmago (core organization)”. E salienta:

Não é apenas, ou mesmo principalmente, pela organização mais eficiente de sua produção interna e de suas transações, ou por suas estratégias de tecnologias de produtos e de suas comercializações, que essa organização atinge seu objetivo, e sim pela natureza e forma das relações que estabelece com outras empresas. (Dunning, 1988, p. 128)

É isso que caracteriza o que Harvey (2005) chama de "acumulação por espoliação", que provém da capacidade que o capital concentrado adquiriu, nas últimas décadas, de crescer alimentando-se de um componente rentista. A empresa-rede é expressão dessa forma de apropriação e centralização, pelo grande capital transnacional, ou capital concentrado, de valores produzidos fora das fronteiras da companhia, por outras empresas menores, ou mais vulneráveis. O leque de relações de terceirização, que adquire sinergia informacional pelas TIC's, contribui para as pulsões sobre a massa bruta de mais-valia das "empresas colaboradoras" (Ohno, 1997).

Nesse novo cenário, os oligopólios de conglomerados transnacionais surgem como os grandes agentes econômicos. A transnacionalização difere de outros movimentos precedentes de integração capitalista, porquanto a divisão mundial do trabalho passou a ser determinada e articula- da por grandes companhias que não mais se submetem aos marcos tributário e legislativo das fronteiras nacionais: ultrapassa-os. É por isso que alguns autores preferem se referir a essas empresas como transnacionais, em substituição à terminologia “multinacional”, mais apropriada ao contexto (inclusive tecnológico) em que suas plantas tinham de se fixar nos países para poder operar. Conforme Bernardo (2000, p. 41), "a divisão em países, que nos habituamos a considerar como forma natural de abordagem da economia mundial, deve hoje ser substituída pela divisão em companhias transnacionais".

Com efeito, em uma economia em que os limites entre lucro e renda estão cada vez mais indistintos, as TIC's tornam-se a principal ferramenta dessa nova forma de lucratividade. Como observa Antonelli (1988), "as empresas-rede (firme réseau, impresa rete ou network firm), por meio da telemática, têm a possibilidade de internalizar importantes externalidades, apoiando-se nas redes (network externalities)". Ele observa ainda que a introdução da telemática leva a "uma queda dos custos médios de coordenação (...) a qual (...) tem sensíveis efeitos na dimensão das atividades organizadas de forma interna nas companhias (...), permitindo assim que empresas maiores funcionem eficazmente" (Antonelli, 1988).

Contudo, essa nova infra-estrutura não poderia cumprir-se inteiramente como tal sem a contrapartida neoliberal. Com efeito, as políticas de desregulamentação, determinadas pelo neoliberalismo foram e são fundamentais para a conformação das redes telemáticas, em consonância com os interesses das transnacionais. A eliminação dos obstáculos legislatórios, tarifários e estatutários, provenientes da administração estatal do conjunto dos meios urbanos necessários ao desenvolvimento industrial, propiciou às grandes companhias transnacionais as condições em que seus interesses podem prevalecer sobre os da nação. Como atenta Bernardo:

Em termos capitalistas perfeitos, o sistema financeiro de cada país não seria mais do que um terminal da rede financeira mundial. E para fun- 
cionar plenamente enquanto terminal será necessário que as autoridades do país reduzam a sua interferência, de maneira a não perturbarem os fluxos de informação que o país recebe do exterior e emite para o exterior (Bernardo, 2000, p. 45).

Por outro lado, posto que os Estados e capitais nacionais, sobretudo dos países periféricos, estão cada vez mais dependentes dos investimentos e inovações tecnológicas do grande capital transnacional, conforma-se uma economia em que as "relações externas mais significativas não se processam já entre países, mas entre companhias transnacionais” (Bernardo, 2000, p. 44). Assim, seja por cooptação e (ou) por fisiologismo de seus governantes, os Estados rendem-se a esse contexto, para assegurarem o desenvolvimento de sua estrutura produtiva. Algo que só pode ser realizado oferecendo-se "força de trabalho qualificada e boas infra-estruturas às companhias transnacionais" (p. 44).

Já os capitais nacionais, para fugirem do risco de obsolescência gerado pela sua desvantagem tecnológica em relação às grandes empresas, são anexados ao capital transnacional, como forma de garantir o acesso às suas inovações e redes de comercialização e, desse modo, não ficarem à parte dos mercados. Em outras palavras:

Para os chefes de empresa de qualquer país, a ligação às grandes companhias transnacionais não é uma opção ideológica ou política. É um imperativo econômico. O nacionalismo não foi apenas condenado como estratégia política, mas, igualmente como prática econômica (p. 43).

Essa imposição também pode ser sentida sob os parâmetros das TIC's, uma vez que a operacionalização dessas redes depende de uma devida padronização, tanto dos softwares utilizados entre empresas de um mesmo grupo e (ou) complexo produtivo, como da sua disposição organizacional. Para além da parte técnica, esses padrões dependem também de um enquadramento às normas, códigos, regulamentos, enfim às particularidades concernentes às atividades específicas de cada setor e, ainda, às distintas legislações e políticas tributária e comercial de cada país.
Dentro desse quadro, as fusões corporativas e a formação de vastos conglomerados setoriais tornam-se a grande tática das organizações de ponta, para evitarem gastos e investimentos redundantes. É a partir desse “imperativo" que se explicam as privatizações que assolaram o setor de telecomunicações do mundo todo, concomitante ao projeto neoliberal (Wolff, 2004). Como alerta Coutinho:

... paradoxalmente, a EDI ${ }^{3}$ permite aumentar um tipo de flexibilidade, de natureza estática, introduzindo, todavia, uma certa rigidez dinâmica. Para ser realmente eficiente, a linguagem de EDI deve ser específica, o que é o oposto de comunicação universal (Coutinho, 1995, p. 29).

Ao permitirem a formação de uma rede informacional capaz de interligar os computadores de distintas empresas em um mesmo padrão de comunicação, as TIC’s proporcionaram um avanço qualitativo e imprescindível para o controle da produção no contexto das organizações transnacionais. A empresa-rede utiliza-se do complexo de subcontratações industriais não apenas para amortecer os efeitos das flutuações conjunturais da economia capitalista instável, fazendo recair sobre suas subcontratadas a crise de mercado, mas para garantir um saber-fazer e rendas "relacionais" derivadas das relações intrafirmas. Trata-se de um vínculo ao mesmo tempo hierarquizado e desonerado, cuja duração é determinada pelo "ciclo de vida" dos produtos.

As transnacionais tornam-se capazes de impor a seus fornecedores, parceiros e distribuidores a transferência de parcelas da lucratividade que essas empresas menores teriam, se operassem as regras de concorrência. Dessa forma, as novas tecnologias em rede concorrem não apenas para a inovação organizacional interfirmas, mas igualmente nas relações intrafirma, cada uma reforçando a eficácia da outra. No quadro de uma "acumulação por espoliação”, os compromissos recíprocos en-

${ }^{3}$ Eletronics Data Interchange - EDI - é a nomenclatura técnica utilizada para designar as conexões, ou redes que operam sob a tecnologia telemática, responsável pela "comunicação de computador a computador de informações geradas por máquinas e que por elas possam ser lidas." (Cf. Coutinho, 1995, p. 27). 
tre empresa montadora e os seus fornecedores estão na origem de uma quase-renda.

Como observa Aoki, esses compromissos constituem uma "renda relacional" na medida em que

... formam benefícios específicos de grupo (group-
specific economic relation) atribuíveis às rela-
ções de cooperação estabelecidas entre a empre-
sa montadora e seus fornecedores. Pode-se desig-
nar estes benefícios como dependentes de uma
quase-renda relacional, no sentido em que é ge-
rada pela incomparável eficiência informacional
das relações contratuais formadas dentro do gru-
po de contratantes (Aoki, 1988, p.67).

Para além dos compromissos recíprocos entre a empresa montadora e seus fornecedores, a constituição da rede informacional permite que a natureza da "espoliação", derivada do saber-fazer relacional dentro da estrutura de integração, seja igualmente refletida nas relações entre essas últimas e seus empregados. No plano organizacional de cada empresa (ou "nódulo") particular, as redes funcionam como um elemento mobilizador da "captura" da subjetividade do trabalho vivo pelo capital (Alves, 2000). Essa mobilização se dá através das novas formas de gestão empresarial por processo inspiradas na chamada administração participativa, que visam a obter a "colaboração" e o pleno engajamento dos diferentes níveis de contratados (Wolff, 2005).

No âmbito interno das empresas, portanto, o modelo rede supõe duas ordens fundamentais de mudança, sendo que uma de natureza material e outra subjetiva, a saber: uma estrutura organizacional integrada, flexível e enxuta, e uma nova cultura produtiva com vistas a estimular o trabalhador a estar aberto a mudanças e afeito a compartilhar informações pertinentes à melhoria da produtividade. Para tanto, privilegia a fluidez da comunicação entre os processos de trabalho, em detrimento do modelo vertical, baseado em hierarquias rígidas, tal como recomenda o taylorismo mais clássico.

É a gestão por processo que contempla uma gestão da informação, que prevê uma maior interação entre as diversas áreas da empresa. É a partir dessa interação que os funcionários podem ter uma visão sistêmica e maior conhecimento dos negócios da empresa, o que permite a concepção de idéias e, certamente, informações mais sintonizadas com os interesses da empresa (Fachinelli, 2002; Lesca; Almeida, 1994). No que se refere à organização do trabalho, é a administração participativa que tem o papel de conformar os trabalhadores para essas mudanças (Wolff, 2005). Política de gestão de pessoal que integra a atual reestruturação produtiva, a administração participativa faculta o modelo rede, ao motivar e direcionar, sistematicamente, a participação e colaboração dos trabalhadores nesse sentido, bem como por despertar uma visão mercadológica com relação ao seu trabalho.

Essa é mais uma faceta pela qual a constituição da rede informacional contribui para a eficácia corporativa, diante das novas formas de concorrência e de apropriação e expropriação de valor diante da "acumulação flexível” e da "acumulação por espoliação".

\section{A TíTULO DE CONCLUSÃO: o ciberespaço e as "possibilidades tecnológicas contraditóri- as" das máquinas informacionais}

O surgimento de objetos técnicos complexos que constituem as redes informacionais altera, de forma qualitativamente nova, a relação entre matéria técnica (objeto de trabalho) e forma organizacional (gestão do trabalho vivo). As novas máquinas informacionais abrem a possibilidade de instauração de formas qualitativamente novas de relações entre homem e máquina. A máquina informacional não é mais máquina em sua materialidade em si, apesar de continuar sendo por conta da forma social do capital. Como já salientamos, a rede informacional como "máquina" implica, em si, a produção de subjetividade, no sentido de colocar, como condição indispensável do processo sistêmico, as habilidades subjetivas (e cognitivas) do trabalho vivo (mesmo que sob forma estranhada). Portanto, o desenvolvimento das 
forças produtivas do trabalho social e o surgimento das novas tecnologias telemáticas e de informação em rede constituíram um novo espaço de sociabilidade virtual apropriado pelo capital.

Em síntese, a revolução das redes informacionais, inserida no novo complexo de reestruturação produtiva, que surge sob a Quarta Revolução Tecnológica, contribui: para a redução dos custos de integração da empresa-rede que surge a partir do oligopólio mundial; para garantir novas formas de rentabilidade derivada das "rendas relacionais”, isto é, das relações entre empresas no curso do complexo de terceirizações e subcontratações industriais; e para uma ofensiva do capital na produção, ativando novas formas de controle do trabalho morto sobre o trabalho vivo, desmontando relações salariais e "flexibilizando" contratos de trabalho.

Sendo assim, com o advento das empresasrede, observamos, até o momento, mais o acometimento de uma teia insidiosa do que propriamente de uma rede ecumênica e inclusiva. Ou seja, as TIC's estão sendo aplicadas sob uma política econômica que reforça e aprofunda os padrões capitalistas de acumulação em uma escala sem precedentes. Isso acontece através da dilatação qualitativa do espaço da propriedade capitalista. Em outras palavras: o modelo rede adotado pelas grandes transnacionais nada mais é que uma forma de promover a privatização da informação que, sob a égide da mundialização do capital, tornou-se o mais novo e indispensável meio de produção das empresas (Gussi; Wolff, 2001).

Contudo, estamos tratando de "possibilidades tecnológicas contraditórias”, como diria Lojkine, que procurou salientar, depois de Marx, que "as características tecnológicas do maquinismo - bem como as da automação - não se confundem com o seu modo de utilização capitalista” (Lojkine, 1995).

Foi com o surgimento das redes telemáticas e, por conseguinte, da Internet, que a idéia de rede informacional assumiu um arcabouço concreto, ou seja, ela passou a representar uma rede de trabalhadores-mediados-por-máquinas-informáticas, não só espalhados pelo globo, mas nas diversas fases da produção, as quais, por seu intermédio, podem, inclusive, ser desenvolvidas fora desse espaço. Surge, assim, o ciberespaço ou a virtualização em rede técnico-informacional. O novo espaço de sociabilidade virtual, o ciberespaço, é um campo de integração difusa e flexível dos fluxos de informações e de comunicação entre máquinas computadorizadas. Um complexo mediador entre os homens, baseado totalmente em dispositivos técnicos, um novo espaço de interação (e de controle) sócio-humano, criado pelas novas máquinas e seus protocolos de comunicação e que tende a ser a extensão virtual do espaço social propriamente dito.

O ciberespaço pressupõe a idéia de redes informacionais como metáfora da cooperação social, que assumiu uma significação concreta com o desenvolvimento do capitalismo tardio. As máquinas informacionais constituiriam a mediação complexa das práticas interativas (e controlativas), o que exige um alto grau de habilidades éticocognitivas (tomada de decisões e escolhas). Por isso, altera-se, de modo qualitativo, a implicação subjetiva entre trabalho vivo e trabalho morto (tecnologia e máquina), o que explica a necessidade de um novo nexo psicofísico na produção do capital.

É assim que, como um espaço de interação sócio-humana de base técnica, o ciberespaço constitui matéria social que abre possibilidades objetivas de produção de subjetividade, estranhada ou não, determinada pelas relações sociais de produção no interior das quais se desenvolve (Alves, 2002). Nesse sentido, o ciberespaço se constitui também como expressão de uma práxis social complexa, que se tornou capaz de desenvolver, em si, novas formas de virtualização. Com isso, surge a possibilidade, e apenas a possibilidade, de o trabalho vivo não ser meramente meio, como ocorria com a máquina da Grande Indústria, mas, sim, pólo ativo de um processo de subjetivação afetado pela categoria de trabalho imaterial, uma forma de trabalho concreto, inscrita na totalidade viva do novo trabalhador coletivo. O processo de subjetivação só existe no âmbito do trabalho imaterial como momento desenvolvido da própria 
produção material (Alves, 2006).

Com o ciberespaço, a máquina é reposta apenas como mediação de uma interação sóciohumana. Nessas condições da "cooperação complexa”, torna (ou devia se tornar) mais clara a relação de sociabilidade entre homem e homem. Entretanto, uma contradição extrema perpassa a lógica sócio-objetiva do capitalismo tardio. Nas condições do controle sócio-metabólico do capital, o fetiche da "máquina" complexa ou "máquina" de inteligência artificial oculta, mais do que nunca, a dimensão estranhada da sociabilidade (Holloway, 2003; Wolff, 2004).

Por isso, a maquinaria da Quarta Idade da Máquina, que constitui o ciberespaço, possui maior grau de fetichização, na medida em que representa, com maior densidade, as contradições ampliadas do sistema sócio-metabólico do capital. Elas possuem, em si, a promessa frustrada (e reprimida) da "pós-máquina" como elo de mediação plena de uma sociabilidade humana omnilateral.

(Recebido para publicação em setembro de 2007) (Aceito em dezembro de 2007)

\section{REFERÊNCIAS}

AGLIETTA, M. Regulación y crisis del capitalismo: la experiencia de los Estados Unidos. México: Siglo Veintiuno, 1979.

ALVES, G. O novo (e precário) mundo do trabalho: reestruturação produtiva e crise do sindicalismo. São Paulo: Boitempo, 2000.

Trabalho e mundialização do capital: a nova degradação do trabalho no capitalismo global. Londrina: Ed. Práxis, 1999.

Alves, G.; MARTineZ, V. (Orgs.). Dialética do ciberespaço. Londrina: Ed. Práxis, 2002.

ANTUNES, R. Adeus ao trabalho? Ensaio sobre as metamorfoses e a centralidade do mundo do trabalho. São Paulo: Cortez, 1995.

Os sentidos do trabalho: ensaio sobre a afirmação e a negação do trabalho. São Paulo: Boitempo, 1999.

(Org.). Riqueza e miséria do trabalho no Brasil. São Paulo: Boitempo, 2006.

ANTONELLI, C. The emergence of the network firm. In:

(Ed.) New information technology and industrial change: the Italian case. Dordrecht: Kluwer Academic Publisher, 1988.

ARANTES, O. Urbanismo em fim de linha: e outros estu- dos sobre o colapso da modernização arquitetônika. São Paulo: Edusp, 1998.

AOKI, M. Information, incentives and Bargaining Structure in the japanese economy. Cambridge/New York: Cambridge University Press, 1988.

BERNARDO, J. Transnacionalização do capital e fragmentação dos trabalhadores: ainda há lugar para os sindicatos? São Paulo: Boitempo, 2000.

BELLUZZO, L.G.M. Valor e capitalismo - um ensaio sobre a economia política. São Paulo: Ed. Bienal, 1987.

BENTHAM, J. O panóptico. Belo Horizonte: Ed. Autêntica, 2000 .

BIANCHETTI, L. Da chave de fenda ao laptop: tecnologia digital e novas qualificações: desafios à educação. Petrópolis: Vozes, 2001.

BIHR, A. Da grande noite à alternativa (O Movimento Operário em crise). São Paulo: Boitempo, 1998.

BOURDIEU, P. WACQUANT, L. A nova bíblia do Tio Sam. In: CATTANI, Alfredo (Org.) Fórum Social Mundial - a construção de um mundo melhor. Petrópolis: Vozes, 2001.

BOYER, R. La fléxibilité du travail en Europe. Paris: Ed. La Découverte, 1986.

BLOCH, E. O principio esperança. Rio de Janeiro: Contraponto, 2005.

BROUSSEAU E; RALLET, A. Evolution organisationnelle et besoins en telecomunications. Etude pour la DPS et la DC/MCA. Paris: France Telecom, 1993.

CHESNAIS, François. A mundialização do capital. São Paulo: Ed. 1996.

(Org.). A mundialização financeira - gênese, custos e riscos. São Paulo: Xamã, 1998.

A finança mundializada - raízes sociais e políticas, configuração, conseqüências. São Paulo: Boitempo, 2005 .

CLARKE, S. Crise do fordismo ou crise da social-democracia? Lua Nova, São Paulo, n.24, p. 117-150, set. 1991.

CORIAT, B. Pensar pelo avesso - O modelo japônes de trabalho e organização. Rio de Janeiro: Revan, 1994.

Ohno e a Escola Japonesa de Gestão da Produção: um ponto de vista de conjunto. In: HIRATA, H. (Org.). Sobre o "Modelo" Japonês . São Paulo: Edusp, 1993.

COUTINHO, L.; CASSIOLATO, J.; SILVA, A. L. G. da. Telecomunicações, globalização e competitividade. Campinas: Papirus, 1995

DELEUZE, G. Conversações. Rio de Janeiro: Editora 34, 1992.

DUNNING, J.H. Explaining international production. London: Unwin Hyman, 1988.

DUARTE, N. Crítica ao fetichismo da individualidade. Campinas: Autores Associados, 2004.

FACHINELLI, A. C. Uma abordagem comunicacional dos princípios da gestão do conhecimento nas organizações. Disponível em: http://www.intercom.Org.br/papers/xxiiici/gt18/gt18a1.pdf

FAUSTO, R. Marx-Lógica \& Política - investigações para uma reconstituição do sentido da dialética. São Paulo: Brasiliense, 1987. Tomo 1.

A "pós-grande indústria” nos Grundrisse (e para além deles). Lua Nova, São Paulo, n.19, nov., 1989.

FOUCAULT, M. Dits et écrits. Paris: Gallimard, 1994. v.4. FONTENELLE, I.A. O nome da marca: McDonald's, fetichismo e cultura descartável. São Paulo: Boitempo, 2002. 
GLYN, A. Os custos da estabilidade: os países capitalistas avançados nos anos 80. In: SADER, E. (Org.). O mundo depois da queda. Rio de Janeiro: Paz e Terra, 1995.

GIUCCI, G. A vida cultural do automóvel: percursos da modernidade cinética. Rio de Janeiro: Civilização Brasileira, 2004.

GOUNET, T. Fordismo e Toyotismo na civilização do automóvel. São Paulo: Boitempo, 1999.

GORZ, A. O imaterial: conhecimento, valor e capital. São Paulo: Annablume, 2005.

GRAMSCI, A. Maquiavel, a política e o Estado moderno. Rio de Janeiro: Civilização Brasileira, 1984.

. Concepção dialética da história. Rio de Janeiro: Civilização Brasileira, 1984b.

GUSSI, A.; WOLFF, S. A "sociedade em rede" e a privatização da informação: escorço de um balanço crítico para refletir a sociedade contemporânea. Temáticas: revista dos pós-graduandos em Ciências Sociais, Campinas, v. 9, n.17/18, p.125-156, jan./dez. 2001.

HARVEY, D. O novo imperialismo. São Paulo: Loyola, 2005.

. Condição pós-moderna: uma pesquisa sobre as origens da mudança cultural. São Paulo: Loyola, 1992.

Los limites del capitalismo y la teoria marxista. México: Fondo de Cultura Econômica, 1990.

HAEFLIGER, S. O assalariado ideal segundo o gerenciamento pós-moderno. Le Monde Diplomatique Online, Paris, maio 2004. Disponível em http:// diplo.uol.com.br/2004-05, a909

HOLLOWAY, J. Mudar o mundo sem mudar o poder: o significado da revolução hoje. São Paulo: Viramundo, 2003.

; PELAEZ, E. Aprendendo a curvar-se: pósfordismo e determinismo tecnológico. Outubro, São Paulo, n. 2, p. 21-29, nov. 1998

IMAI, K.J.; BABA, Y. Systemic innovation and crossborder networks, transcending markets and hierarchies to create a new techno-economic system, In: OCDE. Technology and productivity: the challenge for economic policy. Paris. 1991.

KLEIN, N. Sem logo: a tirania das marcas em um planeta vendido. Rio de Janeiro: Record, 2002.

LÉVY, P. As tecnologias da inteligência - o futuro do pensamento na era da informação. São Paulo: Editora 34 2000.

Filosofia World - o mercado, o ciberespaço, a Consciência. Lisboa: Instituto Piaget, 2000b.

. A inteligência coletiva: por uma antropologia do ciberespaço. São Paulo: Hucitec, 1998.

LESCA H.; ALMEIDA, F. Administração estratégica da informação. Revista de Administração, São Paulo, v. 29, n. 3, p. 66-75, jul./set. 1994.

LUXEMBURG, R. A Acumulação de capital. Rio de Janeiro: Zahar, 1983.

LOJKINE, J. A revolução informacional. São Paulo: Cortez, 1995.

MARX, K.; ENGELS, F. Manifesto Comunista. São Paulo: Boitempo, 1998.

MARX, K. Manuscritos econômico-filosóficos. São Paulo: Boitempo, 2004.

O Capita: crítica da economia política. Rio de Janeiro: Nova Cultural, 1996.

- Capítulo VI Inédito de O Capital: resultados do processo de produção imediata. São Paulo: Moraes, 1985.
. Contribuição à crítica da economia política. São Paulo: Martins Fontes, 1983

MARCUSE, H. Cultura e sociedade. São Paulo: Paz e Terra, 1998

MANDEL, E. Capitalismo tardio. São Paulo: Abril Cultural, 1982.

MATTOSO, J. A Desordem do trabalho. Campinas: Scritta, 1995.

MENEGAT, M. Depois do fim do mundo - a crise da modernidade e a barbárie. Rio de Janeiro: Relume Dumará, 2003.

2006. . O olho da barbárie. São Paulo: Expressão Popular,

MÉSZÁROS, I. Para além do capital: rumo a uma teoria da transição. Campinas,SP: Ed. UNICAMP, 2002.

O século XXI: socialismo ou barbárie. São Paulo: Boitempo, 2003

MORAES NETO, B. Marx, Taylor e Ford: as forças produtivas em discussão. São Paulo: Brasiliense, 1989.

NETTO, J. P Capitalismo e reificação. São Paulo: Livraria Editora de Ciências Humanas, 1981.

OHNO, T. O sistema Toyota de produção: além da produção em larga escala. São Paulo: Bookman, 1997.

PAULO NETTO, J. Capitalismo e reificação. São Paulo: Livraria Editora de Ciências Humanas, 1981.

POCHMANN, M. O emprego na globalização - a nova divisão internacional do trabalho e os caminhos que o Brasil escolheu. São Paulo: Boitempo, 2001.

POSTHUMA, A. C. Restructing and changing market conditions in the Brazilian auto components industry In: KATZ, J. (Org). The automotive industry in Latin America. California-US: Berkley University of California Press, 1994

RAVELLI, M. Economia e modello sociale nel passagio tra fordismo e toyotismo In: INGRAO, P.; ROSSANDA, R. (Orgs.). Appuntamenti di fine secolo. Roma: Manifestalibri, 1995.

ROZENFELD, H. A reestruturação do setor automobilístico brasileiro nos anos 90. In: ENCONTRO NACIONAL DE PÓS-GRADUAÇÃO E PESQUISA EM ADMINISTRAÇÃO, 21, Anais..., 1997.

SALERNO, M. S. Flexibilidade e organização produtiva In: CASTRO, N. A. (Org). A máquina e o equilibrista: inovações na indústria automobilística brasileira. Rio de Janeiro: Paz e Terra, 1995.

SALLES, L.; CAULLIRAUX F. Manufatura integrada por computador: sistemas integrados de produção: estratégia, organização e Recursos Humanos. Rio de Janeiro: Campus/ SENAI COPPE/UFRJ, 1995.

SENNET, Richard. A corrosão do caráter. Rio de Janeiro: Ed. Recor, 1998.

SOUTO-MAIOR, J. Do direito à desconexão do trabalho. Revista do Direito Trabalhista, Brasília, v.10, n.9, 2003.

SCHAFF, A. A sociedade informática. São Paulo: UNESP/ Editora Brasiliense, 1990.

SILVEIRA, P.; DORAY, B. (Orgs.). Elementos para uma teoria marxista da subjetividade. São Paulo: Vértice, 1989.

VIANA, A. R. O capital hegemon: crítica à economia apolítica. 2005. Tese (Doutorado) Programa de Pós-graduação em Sociologia, USP.

WATANABE, B. Toyotismo - um novo padrão mundial de produção? Revista dos Metalúrgicos, São Paulo, 1993. 
WOLFF, S. Informatização do trabalho e reificação: uma análise à luz dos Programas de Qualidade Total. Campinas-SP: Ed. Unicamp; Londrina: Eduel, 2005.

O espectro da reificação em uma empresa de telecomunicações: o processo de trabalho sob os novos parâmetros gerenciais e tecnológicos. 2004; Tese (Doutorado) Instituto de Filosofia e Ciências Humanas-UNICAMP, Campinas

ZARAFIAN, P. Mutação dos sistemas produtivos e competências profissionais: a produção industrial de serviço; valor, organização e competência na produção de serviço esboço de um modelo de produção de serviço. In: Relação de serviço. Produção e avaliação. São Paulo: Senac, 2001.

ZIZEK, S. Fétichisme et subjetivation interpassive. Actuel Marx, Paris, PUF, n.34, 2003.

ZILBOVICIUS, M. Modelos de produção, produção de modelos: contribuição à análise da gênese, lógica e difusão do modelo japonês. São Paulo: FAPESP/Ed. Annablume, 1999. 
CAPITALISMO GLOBAL E O ADVENTO

DE EMPRESAS-REDE: contradições do

capital na quarta idade da máquina

\section{Giovanni Alves \\ Simone Wolff}

A adoção das TIC's pelas empresas de capital concentrado ensejou a implementação de novas estratégias empresariais com vistas à internaciona-lização da produção. Dentre essas, sua estruturação na forma de redes, a qual deu mais poder ao grande capital na luta contra o trabalho organizado. Nesse sentido, as TIC's denotam uma estratégia de ofensiva do capital na produção que altera profundamente as relações entre capital e trabalho. A preocupação central deste artigo é analisar alguns aspectos dos termos e efeitos dessa nova ofensiva, particularmente para aqueles trabalhadores que se encontram no bojo das mutações estruturais do capitalismo global a partir da emergência das chamadas "empresas-rede”.
GLOBAL CAPITALISM AND THE COMING OF COMPANY-NET: contradictions of the capital in the fourth age of the machine

\section{Giovanni Alves \\ Simone Wolff}

The adoption of TIC's by concentrated capital businesses brought the mplementation of new business strategies aiming to the internationalization of the production. Among those, their structuring in the form of networks, which gave more power to big capital in the fight against the unionized work. In this sense, TIC's denote a offensive strategy by the capital in the production that deeply alters the relations between capital and work. The main concern of this paper is to analyze some aspects of the terms and effects of that new offensive, particularly for those workers that are in the midst of the structural mutations of the global capitalism starting from the appearance of the socalled "net- businesses."
LE CAPITALISME GLOBAL ET L'AVÈNEMENT DES ENTREPRISESRÉSEAU: les contradictions du capital au quatrième âge de la machine

Giovanni Alves

Simone Wolff

L'adoption des TIC's par les entreprise de capital concentré a permis l'implantation de nouvelles stratégies entrepreneuriales en vue de l'internationalisation de la production. Entre autres, leur structuration sous forme de réseaux qui a donné plus de pouvoir au grand capital dans la lutte contre le travail organisé. Dans ce sens, les TIC's dénotent une stratégie de combat du capital dans la production qui modifie profondément les liens entre le capital et le travail. La préoccupation centrale de cet article est d'analyser certains aspects des termes et des effets de cette nouvelle offensive, en particulier pour les travailleurs qui se trouvent au cœur des changements structuraux du capitalisme global en partant de l'avènement des dites "entreprises-réseau”.

MoTS-CLÉs: entreprises-réseau, technologies de Palavras-chave: empresas-rede, tecnolo- Keywords: net-businesses, technologies of l'information et de la communication, gias de informação e comunicação, information and communication, cyberespace, contrôle du travail. ciberespaço, controle do trabalho. cyberspace, labor control. 